\title{
Conceive of mechatronic systems
}

\author{
Martin Grossman ${ }^{1, *}$ \\ 1 Development Engineer - Mechatronics, Porsche Engineering Services, Radlická 714/113A, 15800 Praha 5, Czech Republic
}

\begin{abstract}
The paper deals with mechatronic product design stage. Mechatronic product are often complicated and sophisticated product with higher added value. Area of mechatronic is not trivial, because the multi-disciplinary knowledge is needed for design of products. Mechatronic products has improved properties and reliability using the newest know how from all related areas. Many statistics shows, that big portion of products are mechatronic or become to be mechatronics in near future.
\end{abstract}

Keywords: mechatronic, design, concept, system.

\section{Introduction}

The aim of mechatronic design is product with optimal combination of mechanic, electronic and computer engineering, obtained it as soon as possible with minimum costs. Design process can be divided into these stages:

$\checkmark$ conceiving stage,

$\checkmark$ proposing stage,

$\checkmark$ processing stage.

All these stages are composed from elementary operations, which form overall design process.

Mechatronics is as cooperation between specialists from various areas is dominant mainly in conceiving stage of mechatronic product design. Mutual understanding between these specialists is important in order to support expected solution of the designed product. Understanding is important also because of different thinking of various specialists.

Mechanical engineer mainly uses functions of mechanical (electrical) modules and components and it doesn't matter if he (or she) works via using systemic or intuitive approach. Mechanical engineer decomposes expected final functions into functions of subsystems which realize individual physical principles.

Automation engineer uses block scheme and flow of signals. This specialist interesting in modules and components available on market, also interesting in interface, adaptation to electromechanical systems, energy losses, influence of noise and disturbances etc.

Informatics engineer uses mainly time flows and logical conditions. Sequence of commands, loops, branching and dependencies are important for this specialist [1-8].

\section{Describe of mechatronic product properties}

Uniform describing of mechatronic product properties is possible to do via using of these tools:

$\checkmark$ Transformation functions.

$\checkmark$ Target functions.

$\checkmark$ System status. 


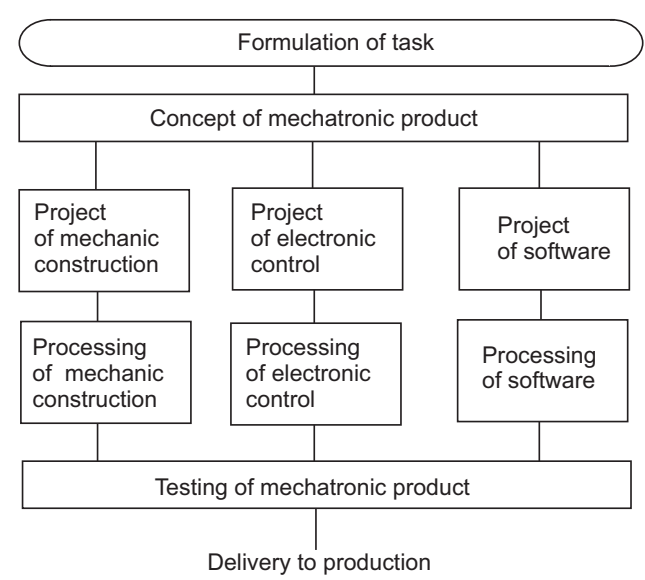

Fig. 1: Mechatronic products construction design stages.

\subsection{Transformation functions}

Transformation function transforms energy, information and material, e.g. DC motor transforms energy, pressure sensor transfers an information and robot displace a material or part. Ion these cases, the mechatronic system appears as structure of transformation functions, what is possible to describe through the block scheme. Figure 2 shows the example where is described structure with transformation functions of intelligent pressure sensor with additional functions as: data acquisition, temperature correction, calibration with built-in etalon, data processing, data storage and data sending etc.

\subsection{Target functions}

Target function represents ability to create necessary physical, chemical or biology phenomena. From this viewpoint, the mechatronic product can be described as structure of target functions. This structure includes all physical phenomena needed for fulfil of mechatronic product target. E.g. transformation function of DC motor is "to create rotation movement". Transformation function of this motor means that electrical power on input is transformed to mechanical rotation on output. Transformation function of DC motor is device for realisation of target function. Figure 3 shows the example of possible structure of target functions of intelligent pressure sensor.

Target function can be structured to functions on lower level (sub functions). For realization of any target function in mechatronic system are necessary all or several from next target sub functions:

$\checkmark$ Energy function - for energy transferring

$\checkmark$ Control function - for controlling of states of the system

$\checkmark$ Interface function - for the conversion of inputs and outputs

$\checkmark$ Protection function - for avoiding of unwanted interactions with environment

$\checkmark$ Communication function - for providing of interaction with other systems

$\checkmark$ Structural functions - for providing of mechanic coupling

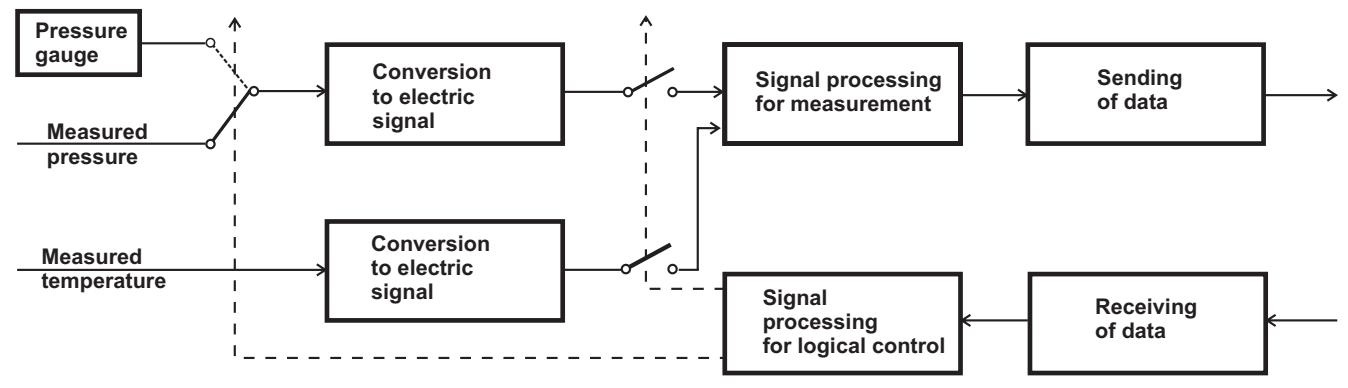

Fig. 2: Intelligent pressure sensor described as structure of transformation functions.

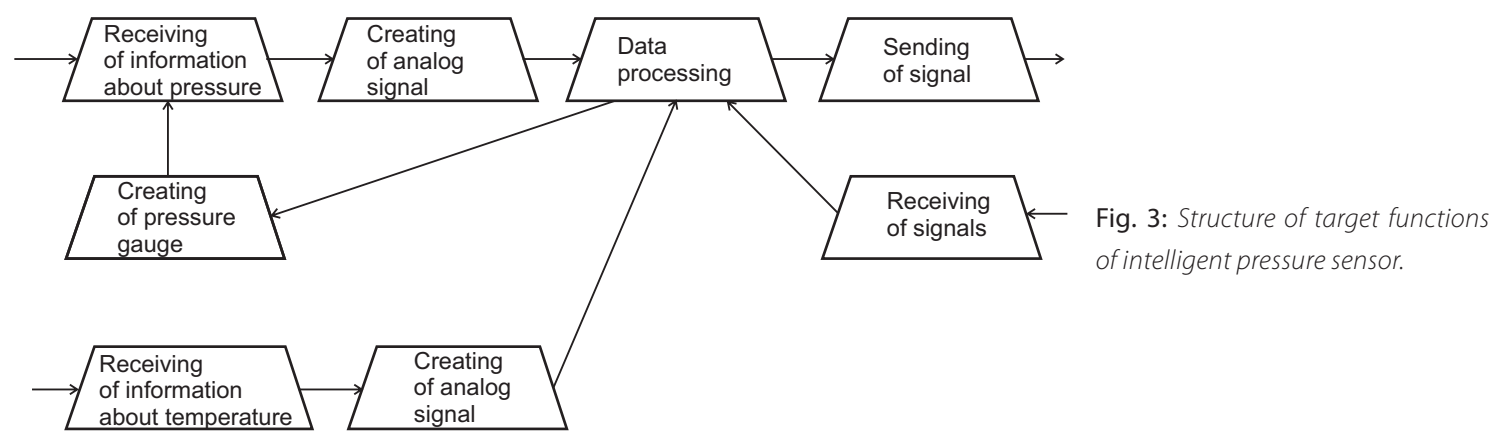




\subsection{System status}

Status of the mechatronic system means a logical situations, which define which transformations will be executed on mechatronic system in the specific status. All mechatronic systems working in several status - minimally two states (on, off). For example, copy machine has 5 states: on, heating, ready, copy and error. Mechatronic system working using different way for every these states. Transition from one status to other status is determined through the logical condition inside the system or the interaction between the operator and mechatronic system. Normally, logical relations are expressed in form: "If (condition) then (transition)"

Representation of mechatronic system status can be expressed with table of transitions or graph of transitions. State description of mechatronic system has to be related to with structure of transformation and target functions. Mechatronic system is working otherwise in every state and this fact causes that also transformation and target functions have to be changed. It means that it is possible to describe different structures of transformation and target functions for various states of the mechatronic system. It can be described also on example of intelligent pressure sensor. Transformation and target function structure can be decomposed to four different structures:

\section{$\checkmark$ measurement, \\ $\checkmark$ calibration, \\ $\checkmark$ source of electric current, \\ $\checkmark$ waiting.}

Target function structure in concrete state can be expressed as activation of these target functions, which are needed for realisation of concrete state. In this case, only some of target functions will be active. Figure 5 shows structure of target functions of the pressure sensor in every of these four states.

Description of mechatronic system with transformation and target function doesn't depend on physical and construction solutions. Concrete solution of mechatronic system needs new terminology. Organ (new term) is a set of components, which use physical, chemical or biology phenomenons for creating of required function. DC motor is example of organ, which uses the electromagnetic phenomenon for creating of rotation motion. The term "organ" is used because of analogy with human body. On the base of it, the mechatronic system we can understand as structure of organs, where every organ realises one or more functions. This approach is frequently used by the most of designers in process of solution design. If designer wants to use the DC motor with any

Waiting Measurement

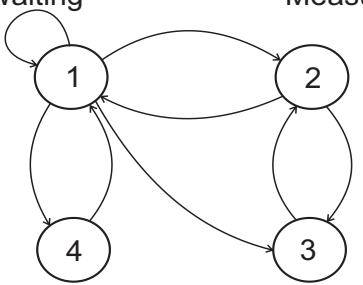

Current

Calibration

power supply
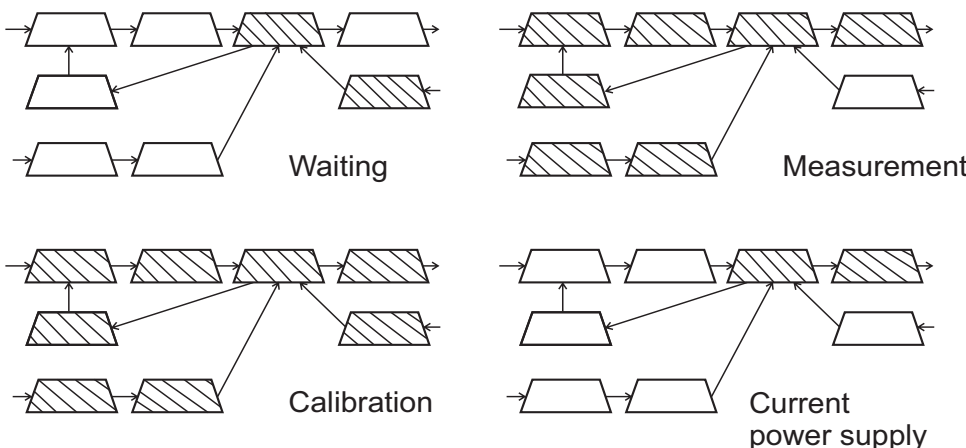

Fig. 5: State diagram and related structures of target functions. 


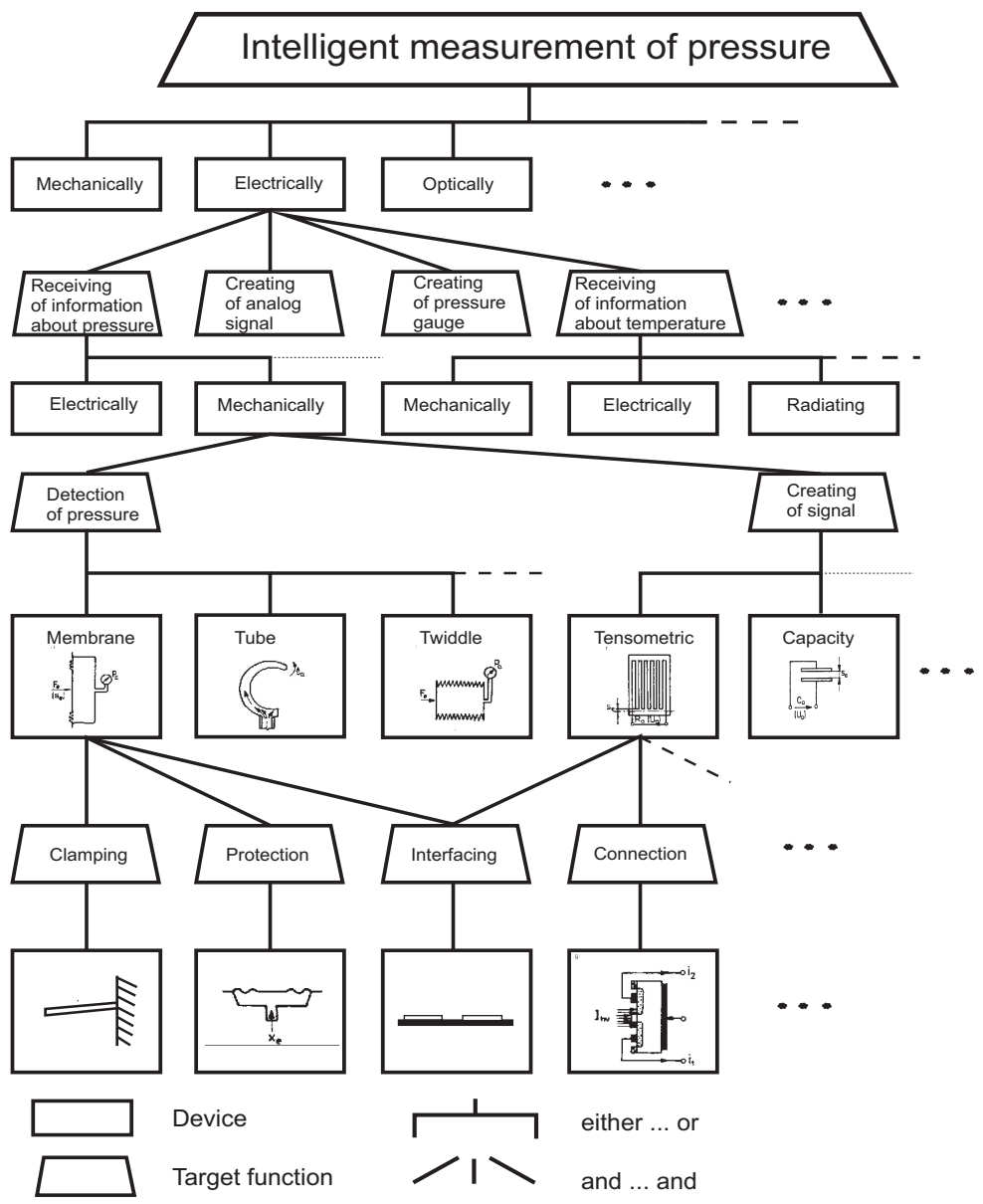

Fig. 6: Tree structure "target function - sub-function - organ" for intelligent pressure sensor.

gears and with position sensor, it means that three organs (DC motor, gear-box, sensor) is inserted into mechatronic system for achieve of required function. Microcontroller cannot be signed as organ if it has no program. Microcontroller is organ only in case if it has any program for achieve any required function. Single program is not organ. Relation between the target function and organ is not only one possible solution. Every organ can realise more functions and for every required function can be used more alternative organs with similar effect. This fact causes that construction design is very difficult but also very interesting.

Causal relation exist between the target functions and organs. Organs ensure the defined target functions on one level, but they need set of subfunctions on lower level. Every sub-function can be realised via using of sub-organs. It can be expressed graphically with tree structure shown on figure 6 . This tree structure shows the hierarchy model of target functions and variant solution of mechatronic system. Set of sub-function is used for finding of concrete organs.

\section{Conclusions}

The aim of this methodology is clear communication between experts in design process of mechatronic products. Design process of mechatronic products require the experts from various areas and they use the different approach in design process. This uniform approach makes the design process more simple and clear.

The main goal is to achieve fast design process as soon as possible. The short design process is important for achieving of good position on market [9-21] 


\section{References and Notes}

[1] Hubka, V., Eder, W.E.: Principles of Engineering Design. Butterworth-Heinemann Ltd; illustrated edition edition (April 1982). ISBN-13: 978-0408011051. 124 pages.

[2] Hubka, V., Eder, W.E.: Design Science. Introduction to the Needs, Scope and Organization of Engineering Design Knowledge. Springer-Verlag London Ltd. 1996

[3] Buur J.: Design models and method for mechatronics. Mechatronic Design in Textile Engineering. ( Edited by Acar. M.), NATO ASI Series: Applied Sciences, Vol.279, pp. 33-46. Kluwer Academic Publishers. Dodrecht. 1995.

[4] Gmiterko, A.: Mechatronics - Mechatronika - driving factors, characteristic and conceving of mechatronic systems. Edition of scientific and technical publications. - SjF TU Košice. Emilena Publishing. 2004

[5] Isermann, R.: Mechatronic Systems. Springer Verlag, 2003, ISBN 1852336935

[6] Shakeri, A.: A methodology for development of mechatronic systems. Ph.D. thesis submited to Norwegian University of Science and Technology. October 1998, ISBN 82-4710340-0

[7] VDI-2206: Design Methodology for Mechatronical System, Beuth, Berlin, 2003.

[8] VDI-2422: Systematical Development of Device Controlled by Microelectronic, Beuth, Berlin, 1994.

[9] Abramov, I. V., Nikitin Y. R., Abramov, A. I., Sosnovich, E. V., Božek, P.: Control and Diagnostic Model of Brushless DC Motor. Journal of Electrical Engineering. Volume 65, Issue 5, Pages 277-282, ISSN (Online) 1339-309X, DOI: https://doi. org/10.2478/jee-2014-0044, November 2014

[10] Březina, T., Hadas, Z., Vetiska, J.: Using of Co-simulation ADAMS-SIMULINK for development of mechatronic systems. MECHATRONIKA, 2011 14th International Symposium. 1-3 June 2011. Trencianske Teplice, ISBN 978-1-61284-821-1, pp. 59-64

[11] Dekan, M., Duchoň, F., Jurišica, L., Vitko, A., Babinec, A.; iRobot Create Used in Education. In: Journal of Mechanics Engineering and Automation. ISSN 2159-5275. Vol. 3, Iss. 4 (2013), s. 197-202.

[12] Koniar, D., Hargaš, L., Hrianka, M.: Application of standard DICOM in LabVIEW. Proc. of 7th conf. Trends in Biomedical Engineering, Kladno 11. - 13. 9. 2007 ISBN 978-80-0103777-5. 2007.

[13] Hargaš, L., Hrianka, M., Koniar, D., Izák, P.: Quality Assessment SMT Technology by Virtual Instrumentation. Applied Electronics 2007, Pilsen, 5. - 6. 9. 2007, ISBN 987-80-7043-537-3, 2007.

[14] Duchoň, F., Dekan, M., Jurišica, L., Vitko, A.: Some Applications of Laser Rangefinder in Mobile Robotics. In: Journal of Control Engineering and Applied Informatics. - ISSN 1454-
8658. - Vol. 14, No. 2 (2012), s. 50-57

[15] Hanzel, J., Duchoň, F., Rodina, J., Pásztó, P.: Global Navigation Systems for Mobile Robots. In: International Journal of Systems Applications, Engineering \& Development. - ISSN 2074-1308. - Vol. 7, Iss. 5 (2013), s. 279-285.

[16] Tölgyessy, M., Chovanec, L’., Pásztó, P., Hubinský, P.: A Plane Based Real-Time Algorithm for Controlling a Semi-Autonomous Robot with Hand Gestures Using the Kinect. In: International Journal of Imaging and Robotics. - ISSN 2231-525X. - Vol. 13, Iss. 2 (2014), pp. 126-133.

[17] Hargas, L., Koniar, D., Simonova, A., Hrianka, M., Loncova, Z.: Novel Machine Vision Tools Applied in Biomechatronic Tasks. Procedia Engineering. Volume 96, 2014, pp 148-156.

[18] Spanikova, G., Spanik, P., Frivaldsky, M. et al.: Electric model of liver tissue for investigation of electrosurgical impacts. Electrical Engineering. 2017. Vol. 99. Issue 4. pp 1185-1194. https://doi.org/10.1007/s00202-017-0625-0.

[19] Kuric, I., Bulej, V., Saga, M., Pokorný, P.: Development of simulation software for mobile robot path planning within multilayer map system based on metric and topological maps. International Journal of Advanced Robotic Systems. 2017. Vol. 14. Issue 6. pp. 1-14. https://doi. org/10.1177/1729881417743029.

[20] Kelemen, M.: Model Based Design of Mechatronic Systems. Acta Mechanica Slovaca 2017, 21(4):8-9.

[21] Rónai, L., Szabó, T.: Kinematical investigation and regulation of a 4DOF model robot. Acta Mechanica Slovaca 2016, 20(3):50-56. 